\title{
Provision of Employer-Sponsored Health Insurance in Small Businesses: Does Rural Location Matter?
}

\author{
Martin Shields, David Mushinski, and Lisa Davis ${ }^{*}$
}

\begin{abstract}
Because employer-sponsored programs are the predominate means by which most non-elderly Americans are covered by health insurance, there is interest in the extent to which observed spatial differences occur because of structural differences in rural and metro economies. We examine factors influencing the costs employers face in providing health insurance to their employees, and how these costs compare in importance to other firm-level and regional economic factors that may impact their decision to offer health insurance to their workers. Overall, we find that costs, rather than either firm-level characteristics or rurality per se, are the most important determinant.
\end{abstract}

Key Words: health insurance; firm size; rural development

JEL classification: I18; J32

\section{INTRODUCTION}

Access to health care in the United States is a prominent policy issue. According to government estimates, approximately 47 million Americans, including 9 million children, had no health insurance in 2006 (U.S. Census August 2007). Millions more people go without insurance for shorter periods of time.

The uninsured are not evenly distributed across the economic and geographic landscape. For example, rural non-elderly adults are less likely to have private health insurance than their urban counterparts (Larson and Hill 2005). Much of this discrepancy is due to differences in employer-sponsored health insurance programs. Previous research has shown that rural employers are less likely to offer health insurance benefits than employers in urban areas throughout most of the United States. Coburn et al. (1998) looked at ten states and found that privately employed rural workers were 10 percentage points less likely to be offered businesssponsored health insurance than urban workers (78 percent versus 88 percent, respectively). Comer and Mueller (1995) and Hartley, Quam, and Lurie (1994) have also found differences in health insurance coverage between rural and urban areas.

A number of policies have been suggested to close the gap in health insurance coverage between rural and urban areas. Some mechanisms are de facto, such as government-sponsored universal health care. Others recommendations are more targeted, building on the unique characteristics of rural areas. For example, the Kaiser Commission on Medicaid and the Uninsured (2003, p. 53) calls for "[s]trategies to increase employers' ability to offer health insurance to their workers that take into account the nature of rural businesses could be helpful at reducing coverage disparities."

\footnotetext{
* Shields and Mushinski are Associate Professors of Economics at Colorado State University. Davis is Director of the Pennsylvania Office of Rural Health, The Pennsylvania State University.

Contact author: Martin Shields, Department of Economics, C323 Clark Building, Colorado State University, Fort Collins, CO 80523. Email: Martin.Shields@colostate.edu

(C) Southern Regional Science Association 2010.

ISSN 1553-0892

SRSA, 1601 University Avenue, PO Box 6025, Morgantown, West Virginia 26506-6025, USA.
} 
When looking at spatial discrepancies in health insurance coverage, understanding how "rurality" affects health insurance coverage is a prerequisite for effective public policy. For example, it is well known that rural and urban economies have important structural differences. It is also known that urban workers, on average, have higher education levels and wages than rural workers. If rural-urban differences in health insurance coverage exist primarily because of spatial variation in industry, workforce characteristics, or both, rather than rurality per se, then policies differentiating solely on the basis of rurality may be misplaced.

In this paper, we provide a profile of the types of small businesses that are more likely to provide health care benefits to employees, paying special attention to the effects of rurality. We focus on employer-sponsored coverage because it is currently the primary means by which the non-elderly insured are covered in the US. This topic is not unexplored. For example, Variyam and Kraybill (1998), who studied employer-sponsored benefit programs for rural small businesses, found that firm size and average wages are more important in the decision to offer health insurance than are factors such as industry and rurality.

Since Variyam and Kraybill's analysis, rapidly rising costs of healthcare and growing insurance premiums have greatly complicated the issue. According to the Kaiser Family Foundation/Health Research and Educational Trust (2007), health insurance premiums increased by an average of 9.5 percent per year between 1999 and 2007, far outstripping worker earnings growth. For businesses that offer health insurance to their employees, such dramatic increases have resulted in important changes in insurance coverage, including higher co-payments and deductibles, reductions in benefits, higher individual contributions, and/or the elimination of health insurance benefits entirely.

The recent rapid increases in health insurance costs may have had notable effects on firms' offer decisions with respect to health insurance. As insurance becomes a larger component of employee compensation, firms might more carefully evaluate their employee compensation packages, including employee contributions to health insurance, dependent-care coverage in health insurance, and coverage of ancillary benefits such as dental insurance. Thus, while firms previously may have focused primarily on the decision to offer health insurance, they may now more carefully analyze their decision to offer health insurance in light of their expected health insurance costs. Stated in other words, the firm offer decision and firm expected health insurance costs may be determined simultaneously.

Our work differs from previous analyses of firm decisions to offer employee health insurance by modeling the simultaneous decisions to offer health insurance and to determine how much of the health insurance cost it should bear. Our primary finding is that the expected costs of an employee's health insurance are the most important determinant in the decision to offer health insurance in the first instance. Another important finding is that rurality does not, in and of itself, have a unique impact on the offer decision. We conclude that the primary way to increase employer-sponsored health insurance offerings is to make it more affordable.

\section{POLICY SETTING}

About 60 percent of the insured non-elderly people in the United States are covered by an employer-sponsored health insurance plan. Thus, employer-sponsored health insurance is the primary means by which working-age people obtain health insurance. The predominance of 
employer-sponsored health insurance is a byproduct of World War II wage and price controls. In light of those controls, employers attracted employees by offering health insurance.

Employer-sponsored health insurance likely predominates today because health insurance purchased by an individual is more costly than group insurance obtained through an employer. Employer-sponsored health insurance tends to be cheaper for two reasons. [For a comprehensive review see Currie and Madrian (1999).] First, unlike wages, employers do not pay payroll taxes on offered health insurance benefits. Thus they can reduce their tax bills by providing insurance, rather than providing greater benefits through wage compensation. Related, employees receive health insurance as a pre-tax benefit, meaning they do not have to pay income taxes on the amount their employer contributes. Second, group-based health insurance obtained through an employer is cheaper than health insurance purchased by an individual because the former type of health insurance pools risks across workers.

For a long time health insurance obtained through, and paid entirely by, an employer worked quite well. Recently, however, the costs of providing medical care have increased substantially. Research has led to great improvements in technology and medical procedures, allowing people to live longer, healthier lives. This effect has been compounded by important innovations in pharmaceutical research. Yet all of this progress costs gargantuan sums of money.

A variety of policy proposals have been forwarded with an eye toward managing costs and increasing the number of Americans with health care coverage. Two themes garnering substantial publicity have been a national single-payer system and employer mandates. The essence of the most prominent single-payer proposal in the U.S. Congress (The United States National Health Insurance Act-HR 676) calls for the federal government to provide every resident health insurance free of charge. Another national proposal calls for expanding Medicaid eligibility to cover more of the low-income uninsured; this proposal does not guarantee universal coverage.

The essence of the employer-mandate proposal is to require that all businesses provide their employees with health insurance. These proposals are more commonly forwarded at the state level, and most outline a "pay-or-play" framework. Here employers can either "pay" a fee to the state to insure their employees or "play" by providing insurance coverage themselves. The Massachusetts Health Care Reform Plan offers a variant of this program, as it requires all adults in the state to purchase health insurance. Under the law, "employers with 11 or more employees are required to provide health insurance coverage or pay a "Fair Share" contribution of up to \$295 annually per employee" (Kaiser Commission on Medicaid and the Uninsured, 2007) .

Not surprisingly, employer mandates have been met with great opposition. The small business community especially fears the substantial added employee costs associated with such mandates. This concern is supported by Meara, Rosenthal, and Sinaiko (2007) who compare three alternative proposals for expanding insurance coverage: employer mandates, Medicaid expansion, and tax credits. With respect to mandates, the study concludes (p. 3): "while the employer mandate may provide the largest drop in the number of uninsured, it does so at the highest cost in terms of lost jobs, foregone wages, and increased employer spending."

We examine small businesses' (defined here as businesses that employ 50 or fewer workers) simultaneous decisions to offer health insurance to their employees and to bear employee health insurance costs. We focus on small businesses because they are much less likely to offer employer-sponsored health insurance than larger ones (Carpenter, 2003). Large 
businesses have more buying power and financial capabilities in the insurance market while small businesses cannot compete in terms of financial viability and risk. Typically, insurance underwriters provide much closer scrutiny when putting together insurance packages for small businesses. Whereas risk pooling affords less oversight for individual workers in large companies, underwriters dealing with smaller businesses often look at the individual employees' health status and preexisting health conditions. Based on this information they then set rates.

In such an environment, one important consequence of recent increases in insurance costs is that small businesses which do provide employer-sponsored insurance may be more likely to experience a dramatic erosion in their ability to remain economically viable and continue to provide health insurance benefits. In response, businesses are asking employees to pay a larger share of the total insurance bill. But this can have important consequences, as businesses that ask employees to pay more may subject themselves to higher employee turnover rates, employee morale problems, and lower product quality.

\section{LITERATURE REVIEW}

Over the past decade several articles have addressed rural-urban differences in health insurance coverage. They have taken one of two tracks. The first examines factors influencing the likelihood that individuals and their families will be insured. This research usually exploits household survey data and considers the effects of various individual, household, and spatial characteristics. Key findings of rural-urban studies include: 1) rural residents are less likely to have employer-sponsored health insurance, especially those most rural (Larson and Hill 2005), and 2) one out of three rural families has at least one uninsured member, a rate higher than for urban families - particularly in nonadjacent counties (Ziller et al., 2008). According to Fronstin (2007), key findings for the nation overall show 1) poor people are most likely to be uninsured, 2) people with a high school degree or less are more likely to be uninsured, and 3) Hispanics and blacks are less likely to be insured.

The second track approaches this question from an employer perspective. This strand is motivated by the fact that employer-sponsored insurance is the primary source of health insurance coverage in the United States. Fundamental interest rests in the extent to which differences in firm decisions to offer insurance are affected by assorted own and spatial characteristics.

Variyam and Kraybill (1998) offer an important example of the employer-based approach. Their findings suggest that firm size and average wages are the primary factors in business decisions to offer health insurance, with larger businesses and businesses paying higher wages being more likely to offer health insurance to their employees. They also find that a firm's industry and its rural status are relatively unimportant. Coburn et al. (1998) offer similar findings, and conclude "[r] ural firms and workers are not behaviorally different from urban firms and workers; they are, however, at a greater disadvantage because of their smaller size and lower wages." From a rural policy perspective, both papers apparently say rural, in and of itself, does not matter.

Although articles that focus singly on the offer decision provide useful insights, they are limited since they often ignore other aspects of employee compensation packages that are determined simultaneously with the health insurance offer decision. As a result, such estimates may not "correctly" account for the notion that insurance offers and wages may be jointly 
determined, and that changes in the cost of insurance might have substantial impacts on wages and vice versa. For example, although relatively few businesses that provide health insurance have completely done away with it for their employees, a large proportion of them are changing the benefits offered by requiring co-payments, imposing co-insurance rates, and requiring deductibles. Thus, despite employers continuing to provide health insurance, employees are bearing a greater percentage of health insurance costs.

A recent paper by Ketsche (2005) addresses this endogeneity issue by modeling the simultaneous determination of total employee compensation and the health insurance offer decision. Specifically, she uses a simultaneous equation model to estimate the propensity of firms to offer health insurance and firms' wage offers. Overall, she finds that uncontrolled endogeneity in single equation models can understate how compensation affects the probability of coverage by more than 50 percent.

We add to the literature on firm health insurance offer decisions by modeling simultaneously a firm's health insurance offer decision and its decision concerning the amount of an employee's health insurance costs it should bear. No studies of which we are aware have attempted to model simultaneously these two aspects of firm compensation decisions. We analyze the firm level, employee, and region level attributes that influence both of these decisions.

In the next section we provide a theoretical model of factors influencing a firm's decision to offer its workers employer-sponsored health insurance. Obviously, an important aspect of the decision is the cost of insurance. Thus, our subsequent empirical model builds on its ancestor by simultaneously examining the factors influencing the costs of providing health insurance to an employee.

\section{THEORETICAL FRAMEWORK}

Labor economists view health insurance as a form of employee compensation that, in some cases, may even be preferable to wages for both workers and firms. As noted above, current US tax law favors employer-sponsored health insurance. At the same time employees may prefer employer-sponsored health insurance to higher wages, as the costs of individualbased insurance may outstrip any additional wage income they receive. Indeed, various recent surveys show that many workers find insurance benefits to be as important as wages when deciding where to work (Fronstin and Helman, 2003). The popularity of employer-sponsored health insurance is derived from the notion that it can lower the total labor costs for firms, while making individual workers better off.

Because benefits are a form of employee compensation, our theoretical model is similar to those of firm wage-offer decisions, with price, firm, and labor market characteristics central. For price, we expect firms to consider the cost of providing insurance coverage to their workers. For firm-specific characteristics we expect scale economies of provision and human capital needs to matter most. Scale economies aid in provision, as firms face substantial fixed costs to administer plans. These can include shopping for providers and plans and learning about various insurance regulations.

With respect to firm level human capital needs, we expect that businesses are more likely to offer insurance if they require a greater composition of highly educated and full-time workers. We suppose this because non-monetary incentives may be necessary to attract such workers in 
competitive labor markets. Further, Currie, and Madrian (1999) argue firms can encourage the self-selection of "desired" employees by offering health insurance, which some workers may prefer to higher wages. In our context, we think of health insurance as an incentive to establish a long-term relationship with experienced, educated workers so as to avoid costly turnover.

Our conceptual model also considers more general local labor market conditions. Our general premise is that firms operating in tight labor markets are more likely to offer health insurance and "better" coverage. In contrast, we expect firms to have greater bargaining power when operating in regions with a relatively slack labor market.

Our interest in rurality intersects with local labor market and human capital notions. Pure theoretical foundations are weaker here, but we might expect that regions with lower population densities behave differently than densely populated places due to structural differences in labor markets. We suspect such differences may manifest themselves through several channels of increased bargaining power on the firm side of the labor market. The rural firm's first source of power is excess local labor supply. As one example, rural places are generally thought to have higher underemployment rates than urban areas (e.g., Jensen, Findeis, and Wang 1999). In such instances firms can offer lower compensation, ceteris paribus, and still attract the necessary workforce.

A second source of a rural firm's comparative compensation bargaining advantage arises from the idea that rural labor demand is less competitive. This can happen due to the relative absence of cluster-type firm concentration in rural areas. According to the urban economics literature, the co-location of similarly oriented firms is a fundamental reason that cities arise and grow. One consequence of spatial concentration, however, is increased labor demand for associated occupations. This serves to enhance the bargaining position of workers, raising their compensation. While the importance of particular industries in rural places is indisputable, it is more likely that fewer firms are competing for similar workers in any given industry, thus potentially providing rural firms with some monopsony or oligopsony power.

\section{EMPIRICAL FRAMEWORK}

Our key objective is to profile the likelihood that various types of small businesses will provide health care benefits to employees, and the extent to which these businesses provide health insurance to their employees. This analysis is based on data obtained in a survey of small businesses in Pennsylvania in 2005. In this section we briefly describe our population, sample and survey procedures. We then turn our attention to the results of an econometric model that identifies the business and regional characteristics that are correlated with providing health insurance benefits.

Our analysis draws on a sample of Pennsylvania businesses listed in the 2003 Quarterly Census of Employment and Wages (QCEW) dataset — provided by the Pennsylvania Department of Labor and Industry (DLI) — and focuses on businesses that employ from 5 to 50 workers. Overall, 1.75 million workers were employed in Pennsylvania businesses in this category in 2003, of which 437,850 were in rural counties. Figure 1 shows the employment for each twodigit NAICS industry in Pennsylvania. It shows that Retail Trade employs the largest number of workers in this category $(359,179$ workers or 20.5 percent of all workers). This is followed by Accommodations and Food Service (218,248; 12.5 percent), Health Care and Social Assistance (213,698; 12.2 percent), and Manufacturing (148,094; 8.5 percent).

(C) Southern Regional Science Association 2010. 
FIGURE 1. Number of Employees by Industry for Rural Businesses with 5-50 Workers: June 2003

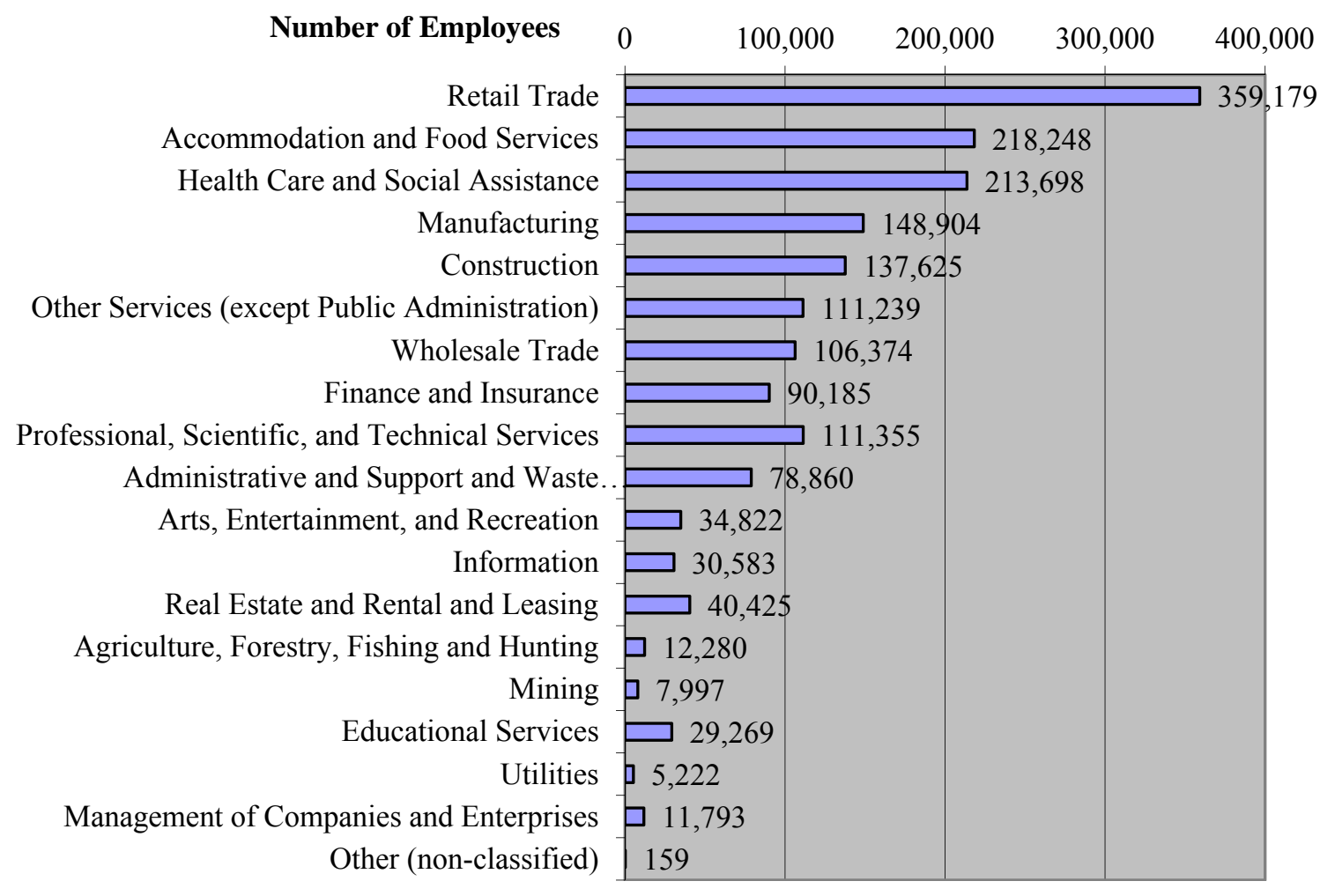

(C) Southern Regional Science Association 2010. 
There is substantial variation in the wages and salaries that these sectors pay. In Table 1 we provide a breakdown of average annual compensation per worker in small businesses for the primary NAICS industries in Pennsylvania. Here we break this down into small-small (5-10 employees), medium-small (11-25 employees), and large-small businesses (26-50 employees), by rural versus urban. The wage is calculated by dividing the average monthly total wages paid by a business in the second quarter of 2003 by the number of employees that business reported for June 2003. This gives an estimated monthly average wage, which was multiplied by 12 to get an annual wage.

Overall, we see two trends. First, urban small businesses tend to pay more per worker than do their rural counterparts. For example, the average total earnings per worker for mediumsmall businesses in urban counties 2003 were $\$ 32,965$, versus $\$ 23,464$ for rural counties. Second, as small businesses grow in size, they tend to pay higher wages. For example, the average annual 2003 wage for a large-small business in rural counties was $\$ 25,214$, whereas small-small businesses in rural counties paid an average wage of $\$ 22,080$.

\subsection{Telephone Survey of Small Business Human Resource Representatives}

As noted above, small businesses face a number of unique challenges in providing health insurance to their employees. To better understand the current situation and trends affecting small business with respect to health insurance benefit provision in Pennsylvania, we conducted a telephone survey of small businesses in the Commonwealth. Overall, the survey consists of completed responses from 711 small businesses - 462 in rural counties and 249 in urban counties. ${ }^{1}$

\subsubsection{About the Sample and the Survey}

Our survey sample was drawn from the June 2003 QCEW. ${ }^{2}$ Because this project focuses on small businesses, the first step in drawing our sample was to select businesses that reported employing between 5 and 50 workers in June 2003. The second step was to identify those businesses in rural counties versus those in urban counties. A third step was to draw a stratified random sample from each of these geographic groups, which we now describe.

One of our objectives in this study was to determine the extent to which workers receive employer-sponsored health insurance in Pennsylvania. Thus, one key component of our sampling procedure was to determine the coverage of employees, rather than coverage provided by employers. This is an important distinction, as the QCEW dataset is designed to cover employers, not workers. Thus, in the original dataset, a simple random sample would mean that all businesses have an equal probability of being selected. However, because Pennsylvania has considerably more very small businesses than medium and large ones, a simple random sample likely would not adequately represent workers.

To correct for this, we stratified our sample by employment size. Specifically, we classified the businesses with between 5 and 50 employees in three groups: 5-10 employees, 1125 employees, and 26-50 employees. We then determined the proportion of all employees in the overall sample in each of these groups. This proportion, in turn, was used to determine the number of businesses drawn from each of the three small business employment classes.

\footnotetext{
${ }^{1}$ We oversampled rural businesses for other purposes in the overall research project.

${ }^{2}$ U.S. Bureau of Labor Statistics, Quarterly Census of Employment and Wages.
} 
TABLE 1. Rural versus Urban Average Annual Wages by Business Size, 2003

\begin{tabular}{lrrrrrr}
\hline & \multicolumn{2}{c}{ Small-Small } & \multicolumn{2}{c}{ Medium-Small } & \multicolumn{2}{c}{ Large-Small } \\
\cline { 2 - 6 } & Urban & Rural & Urban & Rural & Urban & Rural \\
\hline Agriculture, Forestry, Fishing \& & & & & & & \\
Hunting & $\$ 22,155$ & $\$ 18,711$ & $\$ 21,882$ & $\$ 16,952$ & $\$ 22,421$ & $\$ 19,665$ \\
Mining & $\$ 44,709$ & $\$ 31,703$ & $\$ 42,125$ & $\$ 36,963$ & $\$ 49,368$ & $\$ 39,380$ \\
Utilities & $\$ 49,063$ & $\$ 39,921$ & $\$ 66,795$ & $\$ 49,956$ & $\$ 72,585$ & $\$ 58,224$ \\
Construction & $\$ 32,042$ & $\$ 24,329$ & $\$ 39,145$ & $\$ 29,592$ & $\$ 43,771$ & $\$ 35,288$ \\
Manufacturing & $\$ 33,421$ & $\$ 24,826$ & $\$ 37,373$ & $\$ 29,617$ & $\$ 40,362$ & $\$ 31,612$ \\
Wholesale Trade & $\$ 45,078$ & $\$ 30,634$ & $\$ 46,758$ & $\$ 31,290$ & $\$ 47,275$ & $\$ 35,742$ \\
Retail Trade & $\$ 19,948$ & $\$ 16,782$ & $\$ 21,573$ & $\$ 18,800$ & $\$ 23,927$ & $\$ 21,701$ \\
Transportation and Warehousing & $\$ 33,172$ & $\$ 26,958$ & $\$ 34,110$ & $\$ 27,526$ & $\$ 33,900$ & $\$ 28,499$ \\
Information & $\$ 48,466$ & $\$ 29,233$ & $\$ 46,282$ & $\$ 31,167$ & $\$ 48,922$ & $\$ 37,950$ \\
Finance and Insurance & $\$ 42,618$ & $\$ 30,242$ & $\$ 58,340$ & $\$ 37,765$ & $\$ 66,483$ & $\$ 41,118$ \\
Real Estate, Rental and Leasing & $\$ 28,939$ & $\$ 21,000$ & $\$ 30,514$ & $\$ 20,658$ & $\$ 41,705$ & $\$ 21,418$ \\
Professional, Scientific, \& Technical & & & & & & \\
Services & $\$ 47,109$ & $\$ 31,320$ & $\$ 53,415$ & $\$ 35,547$ & $\$ 57,431$ & $\$ 41,911$ \\
Man. of Companies and Enterprises & $\$ 79,835$ & $\$ 41,734$ & $\$ 71,570$ & $\$ 45,245$ & $\$ 60,795$ & $\$ 48,639$ \\
Management and Remedial Services & $\$ 27,775$ & $\$ 21,197$ & $\$ 30,872$ & $\$ 21,199$ & $\$ 31,688$ & $\$ 21,285$ \\
Educational Services & $\$ 26,642$ & $\$ 16,893$ & $\$ 23,567$ & $\$ 19,006$ & $\$ 26,201$ & $\$ 21,549$ \\
Health Care and Social Assistance & $\$ 35,935$ & $\$ 30,292$ & $\$ 38,702$ & $\$ 30,258$ & $\$ 38,187$ & $\$ 25,876$ \\
Arts, Entertainment and Recreation & $\$ 15,406$ & $\$ 9,891$ & $\$ 12,256$ & $\$ 9,770$ & $\$ 13,221$ & $\$ 9,685$ \\
Accommodation, and Food Services & $\$ 11,315$ & $\$ 8,497$ & $\$ 11,346$ & $\$ 8,907$ & $\$ 12,442$ & $\$ 10,271$ \\
Other Services (except Public Admin) & $\$ 21,450$ & $\$ 15,404$ & $\$ 24,187$ & $\$ 17,263$ & $\$ 25,912$ & $\$ 17,685$ \\
\hline Average & $\$ 30,457$ & $\$ 22,080$ & $\$ 32,965$ & $\$ 23,464$ & $\$ 34,227$ & $\$ 25,214$ \\
\hline \hline
\end{tabular}

The telephone survey consisted of three sections. The first section asked basic background information about the business, the products or services provided by the business, and the length of time the business has been in operation. The second section asked the Human Resource Representative to describe the current health insurance coverage - if any-provided to employees and their dependents and the monthly cost per employee to the business of providing health insurance benefits. The survey also asked for information about the type of plan offered by the business (e.g., traditional fee-for-service or "indemnity"), managed care plan (HMO, etc) as well as the types of healthcare services offered, such as dental health, mental health, prescription drug coverage, etc. The financial responsibilities of the employees were also determined, including the monthly amount of employee contribution to the cost of the healthcare plan, co-payments at the time healthcare services are delivered, etc. Human Resource Representatives were asked how the health insurance coverage benefits have changed over the past five years and how the cost to the business has changed during this time period. In the third section, we asked about the role of offering health insurance benefits in attracting and retaining a qualified workforce.

\subsection{Modeling Small Businesses Health Insurance Provision}

Building on our theoretical model and previous empirical research (eg, Variyam and Kraybill, 1998; Ketsche, 2005) we offer an empirical model which simultaneously examines 1) factors influencing the employer cost of health insurance, and 2) the firm health insurance offer decision. Thus, we estimate a Cost Equation and an Offer Equation, and model interdependence 
between the two equations. Here, cost is defined as how much an employer pays per worker for health insurance. We now describe our variables and hypotheses and then turn to our econometric specification. We first present descriptive statistics concerning health insurance costs, as related to number of employees. We then present independent variables included in both equations, followed by the independent variables which appear only in the Cost Equation, and then the independent variables which only appear in the Offer Equation. Means for the variables used in the model, conditional on rural status, are provided in Table 2.

Overall, about 80 percent of both rural and urban responding small businesses reported offering health insurance benefits. As shown in Figure 2, smaller employers that provide health insurance tend to spend more per worker. In urban counties employer costs per employee averaged \$708 in 2005 for businesses with 5-10 workers; in rural counties it was \$638. By comparison, employer costs per employee for businesses with 25-50 employees were \$607 in urban counties and $\$ 561$ in rural counties. Overall, rural small businesses tended to have relatively equal (for mid-size small businesses) or lower costs per employee than their urban counterparts.

\subsubsection{Independent variables in both equations}

Rural. The first variable of interest is the extent to which firm health insurance decisions depend on rurality. Specifically, we examine differences that might result solely from a place of business being located in a rural county. Expectations are that lower population densities may negatively influence labor's demand on businesses to provide health benefits. Empirically, we measure this as a dummy variable, which takes a value of one if a business is located in a rural county (as defined by the USDA Beale Codes). In the cost equation this rural dummy variable is also interacted with several other regressors to determine whether the slope coefficients for those regressors differ in rural areas, as shown in Table 3.

TABLE 2. Variable Means Conditional on Rural/Nonrural Status

\begin{tabular}{lrrr}
\hline \hline Variable & All & Rural & Nonrural \\
\hline Percent Skilled & $51.4 \%$ & $53.0 \%$ & $50.4 \%$ \\
Percent Professional & $15.4 \%$ & $14.3 \%$ & $16.1 \%$ \\
Percent 4-year degree & $14.4 \%$ & $13.3 \%$ & $15.0 \%$ \\
Percent 2-year degree & $8.5 \%$ & $8.5 \%$ & $8.5 \%$ \\
Value added per worker & $\$ 64,870$ & $\$ 68,920$ & $\$ 62,430$ \\
Output per worker & $\$ 117,020$ & $\$ 128,530$ & $\$ 110,100$ \\
1993 Employment & 173,556 & 37,413 & 255,442 \\
$1993-2003$ Employment Growth & $10.6 \%$ & $7.8 \%$ & $12.4 \%$ \\
Rate & & & \\
Business Age & 18.0 & 19.1 & 17.2 \\
Number of Employees & 20.7 & 19.8 & 21.2 \\
Percent Full-time & $70.0 \%$ & $68.0 \%$ & $71.2 \%$ \\
$\ln ($ health costs) & -0.8064 & -0.7787 & -0.823 \\
\hline \hline
\end{tabular}

(C) Southern Regional Science Association 2010. 


\section{FIGURE 2. Average Health Insurance Costs per Worker by Firm Size and Rural/Urban Status}

Q10. Employer Average Per Worker Cost for Health Insurance

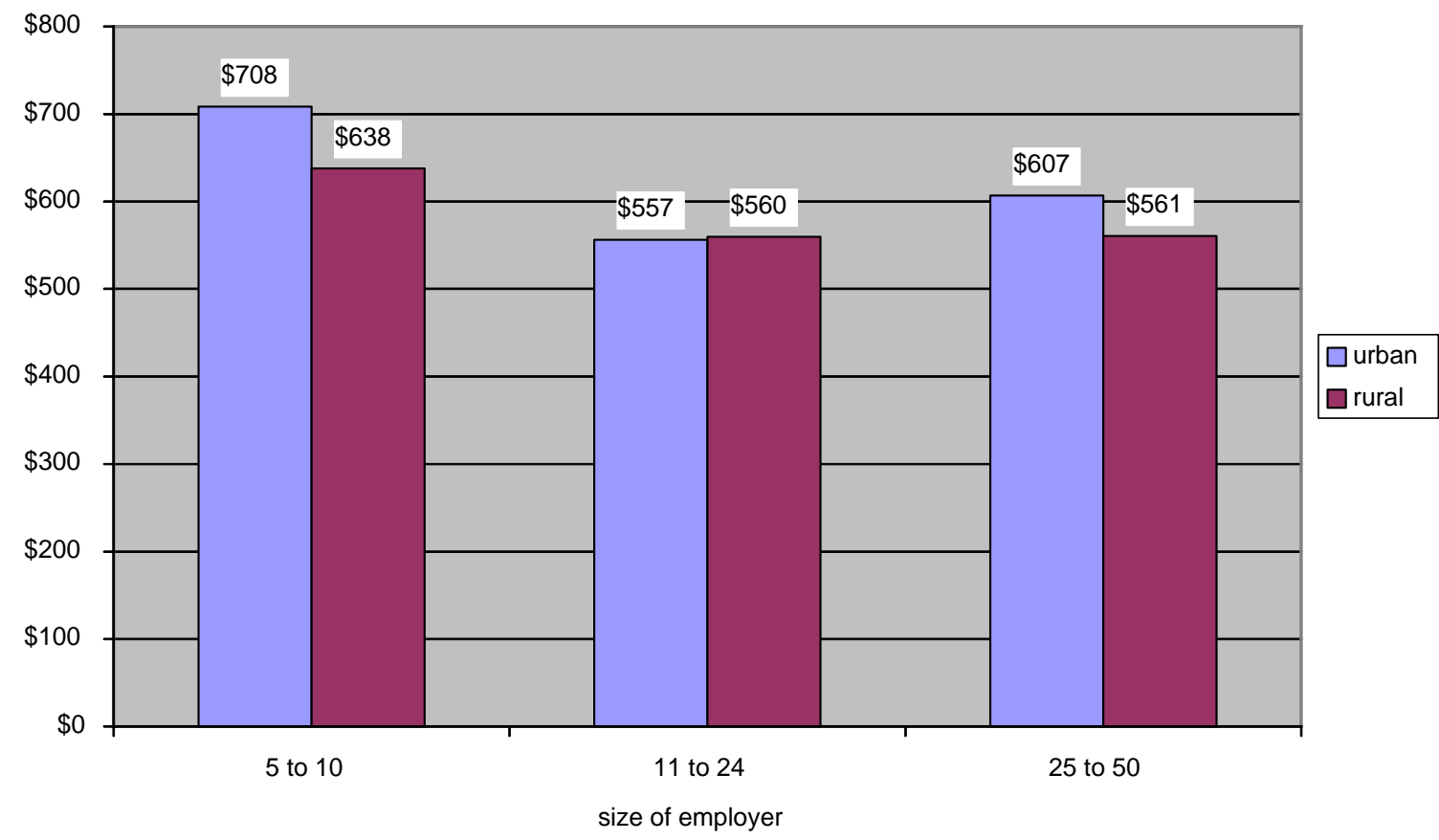

Number of Employees. Economic theory suggests that businesses consider both fixed costs and variable costs when making any business decision. Fixed costs are costs that every business must pay, such as searching for providers. Variable costs are those that businesses pay depending on the level of their provision. For example, businesses providing health insurance typically pay the insurer an established amount per employee. Thus, businesses with more employees will tend to pay more in total for insurance than those with fewer employees. Nonetheless, larger businesses also may tend to pay less per employee than smaller businesses, as they have a more diversified risk pool. That is, with more workers, the risk and subsequent cost of any one worker having a serious illness is spread out over more workers.

Given the combination of fixed and variable costs, theory suggests that larger businesses are likely to have lower health insurance costs per employee than smaller businesses. Thus, we expect that firm size may affect a firm's ability or willingness to pay for health insurance. Variyam and Kraybill (1998) are among those who have found a positive relationship between the number of employees and a business offering insurance (but not for other benefits). Our hypothesis, then, is that businesses with more workers are more likely to provide health insurance than businesses with fewer workers. In our empirical model we use the total number of reported employees as a potential explanatory variable. 
TABLE 3. Estimation results for Health Cost and Offer Equations

\begin{tabular}{|c|c|c|c|}
\hline \multicolumn{2}{|c|}{$\begin{array}{c}\text { Health Cost Equation } \\
\ln (\text { Firm's Health Costs })\end{array}$} & \multicolumn{2}{|l|}{ Offer Equation } \\
\hline Variable & $\begin{array}{l}\text { Parameter } \\
\text { Estimate }^{1}\end{array}$ & Variable & $\begin{array}{l}\text { Parameter } \\
\text { Estimate }^{1}\end{array}$ \\
\hline Intercept & $\begin{array}{l}-0.67^{*} \\
(0.09)\end{array}$ & Intercept & $\begin{array}{l}-51.49 \\
(46.39)\end{array}$ \\
\hline Managed Care (MC) & $\begin{array}{l}-0.29^{*} \\
(0.08)\end{array}$ & $\ln ($ Firm's Health Insurance Costs $)$ & $\begin{array}{l}-73.64^{*} \\
(33.3)\end{array}$ \\
\hline Fee For Service (FFS) & $\begin{array}{l}-0.04 \\
(0.11)\end{array}$ & Value Added Per Worker & $\begin{array}{l}-0.02 \\
(16.7)\end{array}$ \\
\hline Other Health Insurance $(\mathrm{OH})$ & $\begin{array}{l}-0.16^{*} \\
(0.08)\end{array}$ & $\begin{array}{l}\text { Output Per Worker } \\
\text { \% Skilled Employees in Industry } \\
\text { Industry's \% Professional Emps }\end{array}$ & $\begin{array}{l}0.47 \\
(19.16) \\
-0.09 \\
(42.2) \\
-8.61 \\
(27.89)\end{array}$ \\
\hline Business Age $(\div 100)(B A)$ & $\begin{array}{c}0.36 \\
(0.24)\end{array}$ & Business Age $(\div 100)$ & $\begin{array}{l}28.35 \\
(24.6)\end{array}$ \\
\hline Number of Employees (NE) & $\begin{array}{l}-0.30 \\
(0.24)\end{array}$ & Number of Employees & $\begin{array}{l}-22.3 \\
(58.8)\end{array}$ \\
\hline $\begin{array}{r}\% \text { Employees Full Time (PFT) } \\
\text { Rural Variables }\end{array}$ & $\begin{array}{c}0.03 \\
(0.10)\end{array}$ & $\%$ Employees Full-time (PFT) & $\begin{array}{c}2.24 \\
(60.3)\end{array}$ \\
\hline $\begin{array}{l}\text { Rural } \\
(\text { Yes }=1)\end{array}$ & $\begin{array}{c}0.02 \\
(0.15)\end{array}$ & Rural $($ Yes $=1)$ & $\begin{array}{l}-0.56 \\
(9.56)\end{array}$ \\
\hline Rural $\cdot M C$ & $\begin{array}{c}0.01 \\
(0.13)\end{array}$ & $\%$ in Industry with 2-Year Degree & $\begin{array}{l}0.27 \\
(666)\end{array}$ \\
\hline Rural $\cdot F F S$ & $\begin{array}{l}-0.10 \\
(0.19)\end{array}$ & $\%$ in Industry with College Degree & $\begin{array}{l}9.39 \\
(713)\end{array}$ \\
\hline Rural $\cdot O H$ & $\begin{array}{c}0.08 \\
(0.12)\end{array}$ & County Emp Growth 1993-2003 & $\begin{array}{l}0.63^{* *} \\
(0.35)\end{array}$ \\
\hline Rural $\cdot B A$ & $\begin{array}{c}0.06 \\
(0.34)\end{array}$ & County Employment in 1993 & $\begin{array}{l}0.0005 \\
(19.4)\end{array}$ \\
\hline Rural $\cdot N E$ & $\begin{array}{l}-0.17 \\
(0.42)\end{array}$ & & \\
\hline Rural.PFT & $\begin{array}{l}-0.02 \\
(0.17)\end{array}$ & & \\
\hline$R^{2}$ & 0.51 & Log-Likelihood & -42.87 \\
\hline
\end{tabular}

Notes: ${ }^{1}$ Standard errors in parentheses; ${ }^{*}$ Statistically significant at a 5\% level, two-tailed test; ${ }^{* *}$ Statistically significant at a $10 \%$ level, two-tailed test.

Part-time Workers. In the business world, there is usually a sharp distinction in the types of benefits employers provide their full- and part-time employees. Full-time workers are often paid more money for an equivalent amount of output than a part-time employee. Similarly, it might be expected that full-time workers are more likely to have employer-sponsored benefits. In economic theory this is explained by the notion of dual labor markets-one for full-time workers and one for part-time workers. In the full-time labor market, businesses compete differently for workers than they do in the part-time labor market. The full-time worker involves much more investment for the business in terms of both strategic needs and expectations. Thus, businesses 
may need to provide higher compensation to full-time workers than part-time workers, even if they are doing the same type of work. For this reason, we examine the hypothesis that businesses with a higher percentage of full-time workers are more likely to provide health insurance. This information was gleaned from our survey instrument.

Business Age. We examine the hypothesis that businesses that have been around for a longer period of time are more likely to provide employee health insurance benefits. This hypothesis is founded in the notion that longer-standing businesses are more established and, hence, have certain internal advantages that allow them to compete, despite potentially higher costs with respect to worker compensation. That is, a longer-standing firm may have a good reputation that allows it to maintain market share, despite slightly higher costs. Conversely, nascent businesses may need to keep costs as low as possible in order to establish a market presence. In our study, the age of a business is gleaned from survey information. Recognizing that the effects may not be linear with longevity, we also include business age in quadratic form.

Worker Productivity. In Pennsylvania, manufacturing and mining jobs have long been lauded as being "good jobs," since at least in the not-so-distant past they compensated workers well in terms of both wages and benefits. Conversely, retail and service jobs have often been disparaged as "bad jobs," since they have tended to be low-paying and lack benefits. According to data from the Small Employer Health Benefits Survey, almost half of agricultural workers were uninsured and approximately one-fourth of construction and retail workers were uninsured; at the same time, only 12 percent of financial workers were uninsured (Fronstin and Helman, 2000).

Previous work has investigated how industry differences might affect firm offer decisions. To do so, it typically has used industry dummy variables (e.g., manufacturing, retail, etc). While this allows some differentiation across job types, we suggest that the good-bad jobs bifurcation is rooted in worker productivity rather than by industry per se.

We examine whether differences in worker productivity across industries affect a business's ability or willingness to provide health insurance. To do this we use employment and output data from the Minnesota Implan Group (www.IMPLAN.com) to generate per worker estimates of output and value added at the three-digit NAICS level. By using a continuous variable we hope to better unpack variation across industries.

\subsubsection{Variables only in the cost equation}

Plan type and ancillary coverages. Businesses can offer various types of health insurance coverage, and each type can have different costs. We consider three types: 1) managed care, 2) fee for service and 3) other health insurance. We also include a dummy variable that takes the value of one if the firm offers dental coverage.

\subsubsection{Variables only in the offer equation}

Employee skills. One of our key interests is to determine the extent to which employers are likely to provide health insurance to employees according to their skill level. Here, labor theory suggests that there are (at least) two unique labor markets, one for skilled workers and one for unskilled workers. If the skilled labor market is more competitive than the unskilled labor market, then businesses should be more likely to offer health benefits to skilled workers than they are to unskilled workers. In a study of fringe benefit provision by rural small businesses, Variyam and Kraybill (1998) found that both owner/manager educational attainment and worker skill level were significant predictors of offer rates for all benefits. 
To measure worker skills we use the occupation matrix for four-digit NAICS, as provided by the Pennsylvania Department of Labor and Industry. This matrix does several things. First, it identifies all of the occupations for each industry, and the percent of total employment in that industry for each occupation. It then classifies these occupations by education requirements (e.g., high school, college, professional degree) and by skill level (i.e., unskilled, skilled and professional). Here we look at the extent to which businesses' health insurance provision decisions are affected by the skill composition of its workforce. To do this we multiply the total number of employees in a business by the percent of the industry workforce that is considered unskilled and skilled (including professional). In our analysis, then, we examine the hypothesis that employers are less likely to provide health insurance to their employees if there is a relatively high percent of unskilled workers. Our specific variables are the percent of skilled and professional workers in a firm.

We also look at education requirements. Here we use the NAICS-SOC crosswalk to determine the educational mix of various industries. We look at three categories: percent of employees requiring no college degree; percent of employees requiring a two-year degree only; and percent of employees requiring at least a bachelors' degree. We exclude the "no college" category to avoid singularity.

Local labor market trends. In addition to firm and individual employee attributes, economic theory suggests that regional labor market conditions can also affect the likelihood that businesses will provide health insurance benefits to their employees. Specifically, theory would suggest that businesses in more competitive labor markets need to provide workers with increased compensation in order to attract and retain the best workers. This compensation can be through either increased wages or better benefits (e.g., health insurance). Thus, it might be reasonable to expect that businesses with faster growing labor markets are more likely to offer health insurance benefits, all other things equal. As a measure of labor market trends, we examine the total percentage change in county nonfarm employment for the years 1993-2003, using data from the Bureau of Economic Analysis. We hypothesize that small businesses located in counties with higher ten-year employment growth rates are more likely to provide insurance than small businesses located in relatively slow growth counties.

\subsection{The Econometric Model}

We model a firm's decision to offer health insurance $\left(y_{o}\right)$ and its decision regarding the amount of an employee's health insurance costs it will bear $\left(y_{H C}\right)$. We assume that the health insurance costs depend on the independent variables described above: label those variables $\underline{x}_{H C}$. Randomness due to nature and unobserved variables is captured by a disturbance $u_{\mathrm{HC}}$. The Cost Equation is:

$$
\text { (1) } y_{H C}=\underline{\beta}_{H C} \underline{x}_{H C}+u_{H C} \text {. }
$$

We model the insurance offer decision in a latent variable context. Specifically, we assume that the insurance offer decision depends on a latent variable $y_{o}^{*}$, which is affected by $y_{H C}$, the independent variables described above (labeled $\underline{x}_{o}$ ), and a disturbance $u_{o}$. The Offer Equation is

$$
\text { (2) } y_{o}^{*}=\gamma \cdot y_{H C}+\underline{\beta}_{o} \cdot \underline{x}_{o}+u_{o} \text {. }
$$

While $y_{o}^{*}$ is not observed, the offer decision is observed. The offer decision may be modelled as follows: 


$$
\begin{aligned}
& y_{o}=1 \quad \text { if } y_{o}^{*}=\gamma \cdot y_{H C}+\underline{\beta}_{o} \cdot \underline{x}_{o}+u_{o} \geq 0 \\
& =0 \text { if } y_{o}^{*}=\gamma \cdot y_{H C}+\underline{\beta}_{o} \cdot \underline{x}_{o}+u_{o}<0 \text {. }
\end{aligned}
$$

We assume that $\left(u_{H C}, u_{o}\right)$ have a bivariate normal distribution. For identification purposes, we assume that the variance of $u_{o}$ equals one.

We are presented with a simultaneous equation model involving a qualitative dependent variable which depends on a continuous dependent variable. The parameters of this model may be estimated using two-stage least squares methods. Maddala (1983) describes a simultaneousequation model in which the continuous endogenous variable depends on a qualitative endogenous variable and vice-versa. While we are presented with a simpler model, his analysis may be modified to accommodate our model. Stated simply, we estimate the Cost Equation using ordinary least squares, insert predicted values into the Offer Equation, and estimate the Offer Equation in a probit model using maximum likelihood techniques. Maddala (1983) identifies the formula for the variance-covariance matrix of the Offer Equation estimates.

Before discussing the regression estimates, we note that it was necessary to impute the portion of health costs borne by employers who did not offer health insurance to their employees. For each firm not offering health insurance, we imputed to the firm the average portion of the firms offering health insurance in that firm's county. We may interpret the imputed number as the portion of health insurance costs the firm is expected to bear when deciding to offer health insurance.

\section{ESTIMATION RESULTS}

Table 3 reports the regression results. Overall, findings for the Offer Equation are stronger than those for Cost Equation. While an $F$-test of the overall significance of the Cost Equation regression fails to reject the null hypothesis that all parameters on the independent variables equal zero, a likelihood ratio test of the overall significance of the Offer Equation regression rejects a null hypothesis that all parameters for the independent variables in the equation equal zero. ${ }^{3}$ Another method for obtaining insight into the "fit" of the Offer Equation is to determine the extent to which the estimated model accurately identifies whether a firm would offer or not offer health insurance to its employees. Table 4 compares actual firm offer decisions with those predicted by the estimated equation. The estimated model was effective at predicting actual outcomes with only 14 out of the 655 observations mispredicted.

Despite the apparent inability of the independent variables in the Cost Equation to explain much variation in the health insurance costs, two statistical results are of note. First, the negative sign and statistical significance of the parameter estimate for the Managed Care dummy variable indicates that firms which offer managed care face lower health insurance costs than do firms which do not offer health insurance. Second, the negative sign on the Other Health Insurance variable indicates that firms which have chosen health insurance other than fee for service and managed care face lower health insurance costs.

\footnotetext{
${ }^{3}$ The log-likelihood for the Offer Equation under the null hypothesis that the regressors have no collective impact on firm offer decisions equaled -329.15 .
} 
TABLE 4. Goodness of Fit for Offer Equation: Predicted versus Actual

\begin{tabular}{ccc}
\hline $\begin{array}{c}\text { Predicted } \rightarrow \\
\text { Actual } \downarrow\end{array}$ & Offer & Not Offer \\
\hline Offer & 511 & 12 \\
Not Offer & 2 & 130 \\
\hline \hline
\end{tabular}

TABLE 5. Results for Offer Equation with and without Health Insurance Costs as an Independent Variable

\begin{tabular}{|c|c|c|}
\hline Variable & Estimate $^{1}$ & Estimate $^{1}$ \\
\hline \multirow[t]{2}{*}{ Intercept } & -51.49 & $-1.78^{*}$ \\
\hline & $(46.39)$ & $(0.25)$ \\
\hline \multirow[t]{2}{*}{ In(Health Insurance Costs) } & $-73.64^{*}$ & -- \\
\hline & $(33.3)$ & \\
\hline \multirow[t]{2}{*}{ Value Added Per Worker } & -0.02 & $1.51^{*}$ \\
\hline & $(16.7)$ & $(0.49)$ \\
\hline \multirow[t]{2}{*}{ Output Per Worker } & 0.47 & -0.01 \\
\hline & $(19.16)$ & $(0.21)$ \\
\hline \multirow[t]{2}{*}{ \% Skilled Employees in Industry } & -0.09 & 0.06 \\
\hline & $(42.2)$ & $(0.35)$ \\
\hline \multirow[t]{2}{*}{$\%$ Professional Employees in Industry } & -8.61 & 1.67 \\
\hline & $(27.89)$ & $(2.20)$ \\
\hline \multirow[t]{2}{*}{ Business Age $(\div 100)$} & 28.35 & $1.41^{*}$ \\
\hline & $(24.6)$ & $(0.55)$ \\
\hline \multirow[t]{2}{*}{ Number of Employees } & -22.3 & $3.23^{*}$ \\
\hline & $(58.8)$ & $(0.59)$ \\
\hline \multirow[t]{2}{*}{ \% Employees Full Time (PFT) } & 2.24 & $1.14^{*}$ \\
\hline & $(60.3)$ & $(0.22)$ \\
\hline \multirow[t]{2}{*}{ Rural $($ Yes $=1)$} & -0.56 & 0.15 \\
\hline & $(9.56)$ & $(0.14)$ \\
\hline \multirow[t]{2}{*}{$\%$ in Industry with Two-Year Degree } & 0.27 & -0.36 \\
\hline & $(666)$ & $(0.54)$ \\
\hline \multirow[t]{2}{*}{$\%$ in Industry with College Degree } & 9.39 & -0.51 \\
\hline & $(713)$ & $(2.24)$ \\
\hline \multirow[t]{2}{*}{ County Employment Growth 1993-2003 } & $0.63^{* *}$ & -0.27 \\
\hline & $(0.35)$ & $(0.77)$ \\
\hline \multirow[t]{2}{*}{ County Employment in 1993} & 0.0005 & $0.007^{*}$ \\
\hline & (19.4) & $(0.003)$ \\
\hline Log-Likelihood & -42.87 & -241.2 \\
\hline
\end{tabular}

(C) Southern Regional Science Association 2010. 
The lack of statistical significance of the rural dummy variable and its interaction with other independent variables in the Cost Equation suggest that rural firms do not differ from their urban counterparts in terms of their expected health insurance costs. This finding is consistent with prior analyses which find that "rurality" does not in and of itself distinguish firms in rural areas from their urban counterparts.

Two findings of interest emerge from the regression results for the Offer Equation. First, small businesses are more likely to offer health insurance as county employment growth rates increase. This is consistent with the notion that firms located in "tighter" labor markets need to offer additional benefits beyond wages in order to attract and retain workers. Second, the negative sign and statistical significance of the health insurance cost variable indicates that health costs are important to a firm's offer decision. This finding supports our argument that employee health insurance costs and a firm's health insurance offer decision should be modelled simultaneously.

The importance of modelling the health insurance cost and health insurance offer decisions simultaneously is also reflected in a comparison of regression estimates in our model with regression estimates obtained when one does not model that simultaneity. The latter case involves estimating the Offer Equation without the health insurance cost variable. Table 5 includes those regression results for both models. While the Annual Wage, Firm Size, and Percent of Employees Who are Full Time variables are statistically insignificant in the Offer Equation, they become statistically significant when we do not include the health insurance cost variables in the Offer Equation. These results suggest that an approach that does not account for the simultaneity of these decisions might produce misleading results. As a final matter, we note that, in the context of this special issue of The Review of Regional Studies, our results do not indicate that rurality in and of itself has any important effects on the decision that firms make with respect to offering health insurance to their employees.

\section{CONCLUDING COMMENTS}

The effects of rapidly escalating insurance costs are beginning to resonate across the economy. Indeed, many businesses today are more concerned about the rising costs of health care than they are about wage increases. In order to remain competitive in today's global economy, businesses are taking steps to contain these costs. For example, our survey shows that Pennsylvania's small businesses are dealing with escalating costs in a variety of ways, including increasing deductibles, co-pays and employee contributions, and decreasing coverage. Most businesses are also shopping for plans on an annual basis, trying to find cheaper alternative providers, and some are enrolling their employees in Health Savings Accounts. (Although comparing input prices is something all businesses do, constant insurance shopping is a real cost to businesses in terms of human resource time, and to employees who often need to change doctors and other services as providers change.) More dramatic steps involve eliminating coverage of dependents, or, in some cases, eliminating the benefit for the employees themselves. The upshot is that working Pennsylvanians are paying more for their health insurance, taking home less pay, or worse, losing their coverage completely. And there appears to be no end in sight.

In our survey, more than 40 percent of the respondents that offer health insurance benefits have seen their costs of provision increase by an average of 10-20 percent per year over the past 5 years. More astonishing is that about 35 percent report annual costs increasing more 
than 20 percent per year over the past 5 years. Such a model does not seem sustainable. In a global economy, competitive pressures facing Pennsylvania businesses are increasing daily. While improvements in production efficiency through technology have surely helped Pennsylvania businesses to remain globally competitive, there are limits in efficiency gains through technology. Accordingly for most businesses, employees remain the most important resource. But rising health care costs are, in our opinion, a very real threat to the continued viability of Pennsylvania businesses. And any business that tries to contain costs by reducing benefits or increasing employee contributions may run into very real problems in attracting and retaining good workers.

\section{REFERENCES}

Coburn, Andrew, Elizabeth. H. Kilbreth, Stephen. H. Long, and M. Susan Marquis. (1998) "Urban-Rural Differences in Employer-Based Health Insurance Coverage of Workers," Medical Care Research Review, 55, 484-496.

Comer, John and Keith Mueller. (1995) “Access to Health Care: Urban-Rural Comparison from a Midwest Agricultural State," Journal of Rural Health, 11, 128-136.

Currie, Janet and Brigitte C. Madrian. (1999) "Health, Health Insurance and the Labor Market," in Orley Ashenfelter and David Card (eds.), Handbook of Labor Economics, Vol. 3, Part 3. North-Holland: Amsterdam, pp. 3309-3416.

Fronstin, Paul. (2007) "Sources of Health Insurance and Characteristics of the Uninsured: Updated Analysis of the March 2007 Current Population Survey," Employee Benefit Research Institute Issue Brief \#310. Last accessed on September 20, 2010, at www.ebri.org/pdf/briefspdf/EBRI_IB 10-20073.pdf.

Fronstin, Paul and Ruth Helman. (2003) "Small Employers and Health Benefits: Findings from the 2000 Small Employer Health Benefits Survey," Employee Benefit Research Institute. Last accessed September 20, 2010, at http://www.ebri.org/pdf/briefspdf/0103ib.pdf.

Hartley, David, Lois Quam and Nicole Lurie. (1994) "Urban and Rural Differences in Health Insurance and Access to Care," Journal of Rural Health, 10, 98-108.

Carpenter, Dave. (2003) "Why Small Business is Sick over Health Costs." Hospital \& Health Networks, 77, 38-46.

Jensen, Leif, Jill Findeis, and Cindy Wang. (1999) "Labor Supply and Underemployment in the Southern United States," Paper presented at the annual meetings of the Southern Regional Science Association, April 16, Richmond, VA.

Kaiser Commission on Medicaid and the Uninsured. (2007) Massachusetts Health Care Reform Plan: An Update. Available at www.kff.org/uninsured/upload/7494-02.pdf.

Kaiser Commission on Medicaid and the Uninsured. (2003) Health Insurance in Coverage in Rural America Kaiser Family Foundation. Last accessed on September 20, 2010, at www.kff.org/uninsured/upload/Health-Insurance-Coverage-in-Rural-America-PDF.pdf.

Kaiser Family Foundation/Health Research and Educational Trust. (2007). Employer Health Benefits: 2007 Annual Survey Kaiser Family Foundation Last accessed on September 20, 2010, at www.kff.org/insurance/7672/upload/76723.pdf. 
Ketsche, Patricia. (2005) "Employment-Based Health Insurance: Analysis of Rural-Urban Differences in One State," Medical Care Research and Review, 62, 458-478.

Larson, Sharon and Steven Hill. (2005) "Rural-Urban Differences in Employment-related Health Insurance," Journal of Rural Health, 21, 21-30.

Maddala, G.S. (1983) Limited-Dependent and Qualitative Variables in Econometrics. Cambridge University Press: Cambridge, UK.

Meara, Ellen, Meredith Rosenthal, and Anna Sinaiko. (2007) Comparing the Effects of Health Insurance Reform Proposals: Employer Mandates, Medicaid Expansions, and Tax Credits Economic Policy Institute. Last accessed on September 20, 2010, at www.epionline.org/studies/meara 06-2007.pdf.

Variyam, Jayachandran N., and David. S. Kraybill. (1998) "Fringe Benefits Provision by Rural Small Businesses," American Journal of Agricultural Economics 80, 360-368.

Ziller, Erika C. Andrew F. Coburn, Nathaniel J. Anderson, and Stephenie L. Loux. (2008) "Uninsured Rural Families," Journal of Rural Health, 24, 1-11. 